\title{
The role of the central histaminergic system in emergence from propofol anesthesia in rats model
}

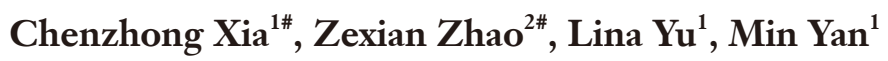 \\ ${ }^{1}$ Department of Anesthesiology, The Second Affiliated Hospital, Zhejiang University School of Medicine, Hangzhou, China; ${ }^{2}$ Department of \\ Neurology, Zhejiang Hospital, Hangzhou, China \\ Contributions: (I) Conception and design: All authors; (II) Administrative support: C Xia, Z Zhao; (III) Provision of study materials or patients: C \\ Xia, Z Zhao, L Yu; (IV) Collection and assembly of data: L Yu, M Yan; (V) Data analysis and interpretation: C Xia, Z Zhao, L Yu; (VI) Manuscript \\ writing: All authors; (VII) Final approval of manuscript: All authors. \\ \#These authors contributed equally to this work. \\ Correspondence to: Min Yan. \#88 Jiefang Road, Hangzhou 310000, China. Email: zryanmin@zju.edu.cn.
}

Background: The mechanisms of emergence from general anesthesia remain to be elucidated. Recent studies indicate that the central histaminergic system plays a critical role in maintaining wakefulness. In addition, the neural pathways that regulate the wake-sleep cycle are involved in general anesthesia. In this study, we determined the role of the central histaminergic system in emergence from propofol anesthesia using microinjections and single-unit recordings in rats.

Methods: All rats were implanted with unilateral guide cannulae or bilateral cannulae. Return of righting reflex could be used as an index of recovery of consciousness in rats. Neuronal activity was collected. The placement of the injection cannulae and/or microelectrodes was verified in coronal sections $(10 \mu \mathrm{m}) \mathrm{cut}$ with a cryostat microtome. Animals with incorrect placements were removed from this study. The neuronal activity was subjected to an off-line clustering analysis (K-means) using the Plexon Off-line Sorter to identify one or more individual units recorded from the same electrode from each other and noise.

Results: We found intracerebroventricular (icv) microinjections of histamine decreased the emergence time in a dose-dependent manner and had an excitatory effect on the firing activity of medial prefrontal cortex (mPFC) neurons, while the decrease of emergence time was completely reversed by the pre-treatment with triprolidine $(80 \mu \mathrm{g} / 5 \mu \mathrm{L})$ but not cimetidine $(100 \mu \mathrm{g} / 5 \mu \mathrm{L})$. Moreover, the presumed histaminergic neurons fired in a state-dependent manner, and there was a dramatic increase in firing activity before regain of righting reflex. Furthermore, bidirectional manipulations of emergence were achieved through the microinjection of gamma-aminobutyric acid (GABA) $(10 \mu \mathrm{g} / \mathrm{side})$ and a potent $\mathrm{H} 3$ receptor inverse agonist ciproxifan $(1 \mu \mathrm{g} /$ side) into the posterior hypothalamus, where the tuberomammillary nucleus (TMN) resides. Combine the behavioral and neurophysiologic evidence, the central histaminergic system promotes emergence from propofol anesthesia in rats.

Conclusions: Our findings suggest an important role of the central histaminergic system in a broader field of state transitions, such as emergence from propofol anesthesia.

Keywords: Central histaminergic; general anesthesia; emergence; medial prefrontal cortex (mPFC)

Submitted Dec 25, 2020. Accepted for publication Apr 02, 2021

doi: 10.21037/apm-20-2594

View this article at: http://dx.doi.org/10.21037/apm-20-2594 


\section{Introduction}

General anesthesia is a transient and reversible consciousunconscious state transition induced by general anesthetics (1). Millions of patients receive general anesthesia for surgery every year, and in most patients, rapid emergence from general anesthesia is desirable $(2,3)$. A major index of emergence is the recovery of consciousness. However, the mechanisms of emergence are not well understood. Previous studies have suggested that there were a lot of similar physiologic and behavioral traits between general anesthesia and non-rapid eye movement sleep state (4-7). Currently, the basic neural pathways underlying the regulation of the wake-sleep cycle form a flip-flop switch that enables rapid and complete state transitions (8-10). Therefore, it brings about the supposition that emergence from general anesthesia and the wake-sleep cycle share some common neural substrates $(5,7,11)$.

The tuberomammillary nucleus (TMN) of the posterior hypothalamus, is the exclusive region that contains histaminergic neurons (12), also known as an arousal system in the flip-flop switch (9). Nelson et al. have found propofol decreases c-fos expression in the TMN (13) and similar changes were observed during non-rapid eye movement sleep (14). In addition, administration of muscimol into TMN produces dose-dependent sedation (13). Mice that carry a specific mutation in the gammaaminobutyric acid $(\mathrm{GABA})_{\mathrm{A}}$ receptor $\beta_{3}$ subunit $(\mathrm{N} 265 \mathrm{M})$ in the TMN showed a decreased sensitivity to propofol (15). These findings have indicated that TMN was a direct target site of GABAergic anesthetic. A subsequent study has shown that the application of histamine to the nucleus basalis magnocellularis induces electroencephalographic activation during isoflurane anesthesia (16). Rats with bilateral TMN lesions increased the sensitivity to isoflurane and prolonged emergence time (17). Although it is widely known that distinct molecular mechanisms are mediated in two commonly used general anesthetics (isoflurane and propofol) (11), neural pathways that mediated the emergence from general anesthesia remain to be investigated. Additionally, emergence from general anesthesia is different from the common belief which regards it as an inverse process of induction of general anesthesia. Other monoaminergic arousal nuclei, such as the ventral tegmental area (18) and locus coeruleus (19), have been found involved in emergence. Here, we propose that emergence from propofol anesthesia may recruit the central histaminergic system. The medial prefrontal cortex (mPFC), a key region responsible for a variety of cognitive functions (20-22), receives intensive histaminergic innervation from TMN (23). The existence of these projections suggests that histaminergic neurons are intimately involved in regulating the activity of mPFC neurons. Consciousness and cognition are progressively recovered during emergence from anesthesia, whereas much of the research in the general anesthesia field is performed using electroencephalogram in rats without direct evidence available in the activity of $\mathrm{mPFC}$ neurons. So far, the activity of $\mathrm{mPFC}$ neurons during emergence has not been studied. Therefore, in the present study, we investigated the role of the histaminergic system on emergence time and the firing activity of $\mathrm{mPFC}$ neurons by using single-unit recording in rats during emergence from propofol anesthesia.

We present the following article in accordance with the ARRIVE reporting checklist (available at http://dx.doi. org/10.21037/apm-20-2594).

\section{Methods}

\section{Animals}

Adult male Sprague-Dawley rats, weighing 250-330 g, were used in this study. They were housed individually at a constant temperature $\left(24 \pm 0.5^{\circ} \mathrm{C}\right)$ on a 12 -h light-dark cycle (light on at 7:00 AM and off at 7:00 PM) and allowed free access to food and water. Experiments were performed during the light phase. The flow chart of the study was shown in Figure 1.

Experiments were performed under a project license (No.: 2019-676) granted by the Animal Care Committee of Zhejiang University, in compliance with institutional guidelines for the care and use of animals.

\section{Surgery}

Surgery was performed using standard, aseptic and stereotaxic techniques under sodium pentobarbital anesthesia (60 mg/kg, ip). Rats were implanted with guide cannulae for drug application and/or microelectrode array composed of 4 microelectrodes (diameter $35 \mu \mathrm{m}$, impedance 1-2 M $\Omega$ ), arranged in $2 \times 2$ configurations with a separation between the tips of approximately $300 \mu \mathrm{m}$. All rats were implanted with unilateral guide cannulae or bilateral cannulae. Unilateral guide cannulae were implanted according to the following coordinates from bregma: anteroposterior $(\mathrm{AP})=-0.6$; lateral $(\mathrm{L})=-1.4$; dorsoventral $(\mathrm{DV})=-2.9$; 


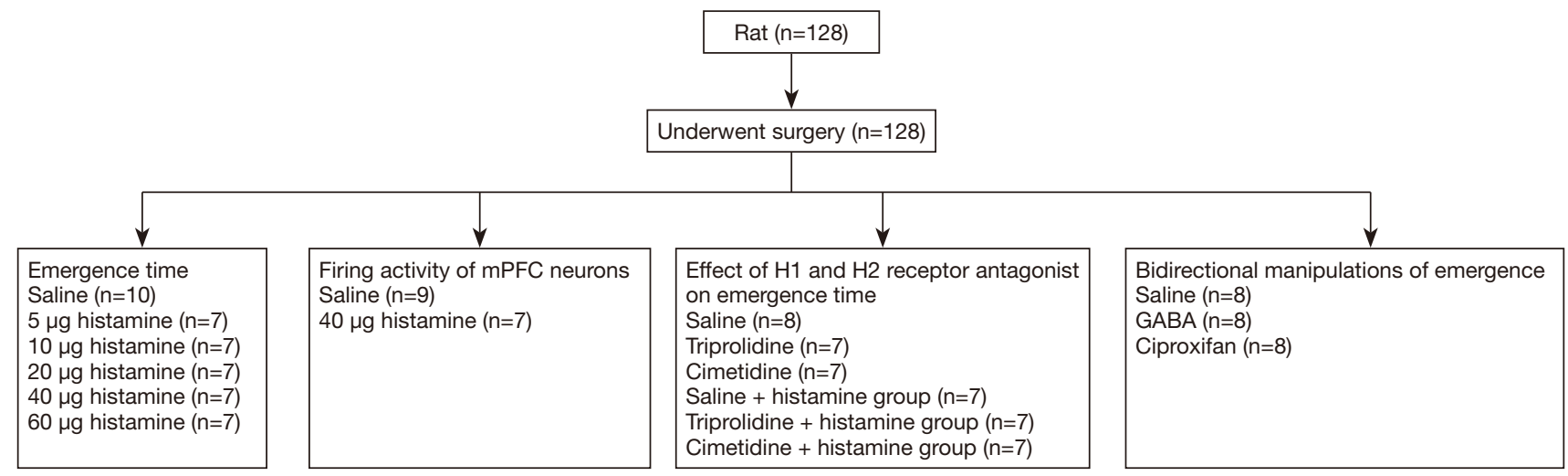

Figure 1 Flow chat. GABA, gamma-aminobutyric acid.

$1.0 \mathrm{~mm}$ above the lateral ventricle (LV) (24). Bilateral cannulae were implanted according to the following coordinates: $\mathrm{AP}=-4.2, \mathrm{~L}= \pm 1.0, \mathrm{DV}=-7.2 ; 2.0 \mathrm{~mm}$ above the TMN. Rats were chronically implanted with microelectrodes for extracellular activity recordings. A craniotomy was performed to expose the cortex overlying the left TMN (AP $=-4.2, \mathrm{~L}=-1.0, \mathrm{DV}=-9.2)$ or $\mathrm{mPFC}(\mathrm{AP}=-3.0, \mathrm{~L}=-0.7$, $\mathrm{DV}=-3.5)$, and the tips of the microelectrodes were lowered into the recording region using a micromanipulator (RWD, model: 68102; Shenzhen, China). The guide cannulae and/or microelectrodes and four stainless steel screws for anchorage were fixed to the rat's skull with dental cement. All the animals received penicillin (20,000 IU) immediately after surgery and then recover for at least 7 days before experiments began.

\section{Propofol anesthesia}

Rats received propofol $(10 \mathrm{mg} / \mathrm{kg}$, iv) for induction of anesthesia. Maintenance of anesthesia was achieved with continuous infusion of propofol through the tail vein at $40 \mathrm{mg} / \mathrm{kg} / \mathrm{h}$ for 15 minutes. The induced dose was chosen because it was about twice the EC50 dose for loss of righting, and the continued infusion was adopted to simulate the clinical anesthesia.

\section{Pharmacological treatment}

The following drugs were purchased from Sigma Aldrich, histamine (H 7125), triprolidine ( $\mathrm{T}$ 6764), cimetidine (C 4522), GABA (A 5835), and ciproxifan (C 6492).

To investigate the effect of exogenous histamine on emergence, either normal saline or histamine solution
(5 $\mu \mathrm{g} / 5 \mu \mathrm{L}$ to $60 \mu \mathrm{g} / 5 \mu \mathrm{L}$ ) was injected into the $\mathrm{LV}$ via guide cannula at 9 min post general anesthesia. Briefly, a 30 -gauge injection needle, protruding $1 \mathrm{~mm}$ below the tip of the guide cannulae, was connected to a $10-\mu \mathrm{L}$ Hamilton syringe driven by a micro-pump (World Precision Instruments, model: UMC4; FL, USA) at $1.5 \mu \mathrm{L} / \mathrm{min}$. A total volume of $5 \mu \mathrm{L}$ was injected (200 s injections), then the needle was left in place for $60 \mathrm{~s}$ to allow the diffusion of the drug. To determine the specific histamine receptor underlying the effect, rats were pretreated with saline or $\mathrm{H}_{1}$ receptor antagonist triprolidine $(80 \mu \mathrm{g} / 5 \mu \mathrm{L})$ or $\mathrm{H}_{2}$ receptor antagonist cimetidine $(100 \mu \mathrm{g} / 5 \mu \mathrm{L})$ at 3 min postgeneral anesthesia. These concentrations were adjusted to completely block the $\mathrm{H}_{1}$ and $\mathrm{H}_{2}$ receptors, respectively.

To evaluate the effect of TMN on emergence, bilateral intracerebral injections of saline or GABA or a potent $\mathrm{H}_{3}$ receptor inverse agonist ciproxifan were performed at $0.4 \mu \mathrm{L} / \mathrm{min}$ at $12 \mathrm{~min}$ post-general anesthesia. A total volume of $0.2 \mu \mathrm{L} /$ side was injected ( $30 \mathrm{~s}$ injections), then the injection cannula was left in place for $60 \mathrm{~s}$ to allow the diffusion of the drug. GAGA was were dissolved in normal saline solution to reach a final concentration of $50 \mathrm{mg} / \mathrm{mL}$. Ciproxifan (C 6492, molecular mass: 306.79), was dissolved in normal saline solution to reach a final concentration of $5 \mathrm{mg} / \mathrm{mL}$ (about $1.6 \times 10^{-5} \mathrm{~mol}$ ). This concentration was chosen based on one study showing that the $\mathrm{H}_{3}$ receptor was almost fully inhibited by ciproxifan at a concentration of $1.0 \times 10^{-5} \mathrm{~mol}$ and revealed a linear correlation between the ex vivo inhibition of specific binding and brain concentration (25).

\section{Emergence time}

Return of righting reflex could be used as an index of 
recovery of consciousness in rats. In this study, the rat was placed in the supine position, and the time to regain the righting reflex after the termination of propofol infusion was defined as the emergence time.

\section{Recordings}

Neuronal activity was collected with OmniPlex D Neural Data Acquisition System (Plexon Inc., TX, USA) and sampled at $40 \mathrm{kHz}$. Awake rats were first placed into the experimental chambers for $30 \mathrm{~min}$. As rats were usually active for the first few minutes to explore the chamber rapidly. When rats adapted to the new environment, baseline recordings were taken for $3 \mathrm{~min}$ in wakefulness before anesthesia. Next, the animals were anesthetized with propofol. Neuronal recordings in TMN were taken for 3 min during the general anesthesia state at $5 \mathrm{~min}$ after propofol infusion. Neuronal activities were recorded continuously throughout emergence.

\section{Histology}

After completion of the emergence evaluation, rats were deeply anesthetized with sodium pentobarbital, and recording sites were marked with electrolytic lesions (20 $\mu \mathrm{A}, 3 \mathrm{~min})$. Then rats were perfused transcardially with saline, followed by $4 \%$ paraformaldehyde in phosphate buffer. The brains were removed and immersed in 30\% sucrose solution, overnight. The placement of the injection cannulae and/or microelectrodes was verified in coronal sections $(10 \mu \mathrm{m})$ cut with a cryostat microtome. Animals with incorrect placements were removed from this study.

\section{Data analysis}

The neuronal activity was subjected to an off-line clustering analysis (K-means) using the Plexon Off-line Sorter (Plexon Inc., TX, USA) to identify one or more individual units recorded from the same electrode from each other and noise. Single neurons were identified as follows: (I) a consistent waveform shape across time; (II) the amplitude of the signal was at least three times larger than background activity. TMN histaminergic neurons were distinguished from other neighboring neurons according to well-established criteria (26), including their location, unique long-duration waveform with prominent negative phase, and slow irregular firing rate. NeuroExplorer (Nex Technologies) was used for further analysis of firing activity.
Firing activities during emergence were converted to \% of baseline (firing rate per $60 \mathrm{~s}$ during emergence/average firing rate during $180 \mathrm{~s}$ baseline) for each neuron.

\section{Statistical analysis}

Data were expressed as mean \pm standard deviation (SD). Statistical analyses were performed using SPSS 16.0. The normality of the data was tested by the Shapiro-Wilk test. The intra-group analysis was performed by one-way ANOVA or two-way ANOVA with repeated measures on time (one variable) among groups. Post hoc between-group comparisons of specific samples were performed using Dunnett's test. The significance level was set at two-sided $\mathrm{P}<0.05$ for all statistical tests.

\section{Results}

\section{Histological analysis}

The microelectrode and/or cannulae were confirmed to be located in the correct areas without abnormal tissue damage by $\mathrm{H} \& \mathrm{E}$ staining (Figure 2).

\section{Histamine decreases the emergence time}

Microinjections into the $\mathrm{LV}$ of saline (control) or histamine at the dose of $5,10,20,40$, and $60 \mu \mathrm{g}$ were performed in rats implanted with the cannulae, the protocol for this experiment was displayed in Figure $3 A$. The average time to emergence for rats that received normal saline $(\mathrm{n}=10)$ was $493.40 \pm 36.06 \mathrm{~s}$. Injections of histamine resulted in a dose-dependent decrease in emergence time [one-way ANOVA, $\left.\mathrm{F}_{(5,41)}=9.661, \mathrm{P}<0.001\right]$ (Figure 3B). For rats that received histamine of $5,10,20,40$ and $60 \mu \mathrm{g}$, the average time to emergence was $485.56 \pm 32.68 \mathrm{~s}(\mathrm{n}=9), 454.29 \pm$ $23.00 \mathrm{~s}(\mathrm{n}=7), 409.42 \pm 15.57 \mathrm{~s}(\mathrm{n}=7), 302.57 \pm 34.16 \mathrm{~s}(\mathrm{n}=7)$ and $272.71 \pm 21.45 \mathrm{~s}(\mathrm{n}=7)$, respectively. As shown in Figure $3 B$, the emergence time was significantly decreased by both histamines at the dose of $40 \mu \mathrm{g}$ (Dunnett's test, $\mathrm{P}<0.001$ ) and $60 \mu \mathrm{g}$ (Dunnett's test, $\mathrm{P}<0.001)$ compared with the saline group. Nonetheless, there was no significant difference in emergence time between histamine 40 and $60 \mu \mathrm{g}$ (Dunnett's test, $\mathrm{P}=0.941$ ).

\section{Excitatory effect of histamine on the firing activity of mPFC neurons}

We further assessed the potential effect of histamine 

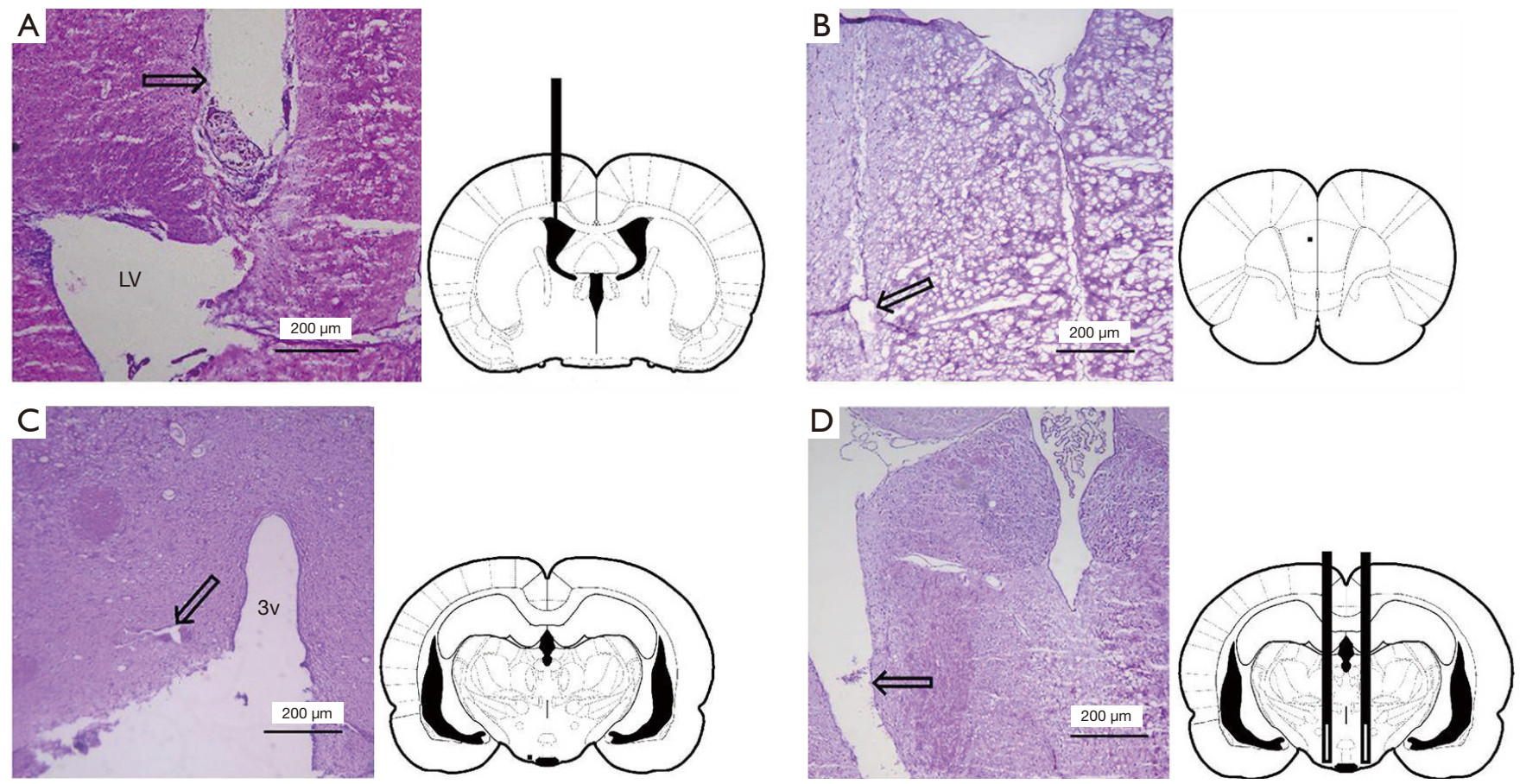

Figure 2 Photomicrographs (left panel) and schematic representations (right panel) of the anatomical locations of the cannulae and microelectrode. (A) Coronal section of a rat implanted with the guide cannulae $1 \mathrm{~mm}$ above the lateral ventricle for microinjections and schematic representation of the implantation site; (B) recording site in mPFC; (C) recording site in TMN; (D) the guide cannulae 2 mm above the TMN for microinjections. Arrowheads indicate the cannulae and microelectrode traces. H\&E staining. mPFC, medial prefrontal cortex; $\mathrm{LV}$, lateral ventricle; $3 \mathrm{v}$, the third ventricle.

A

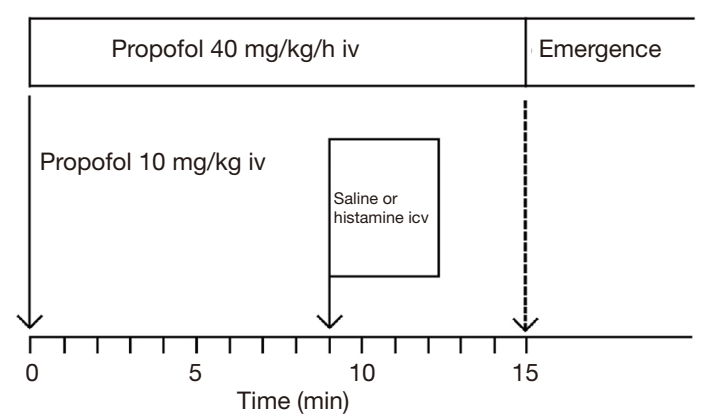

B

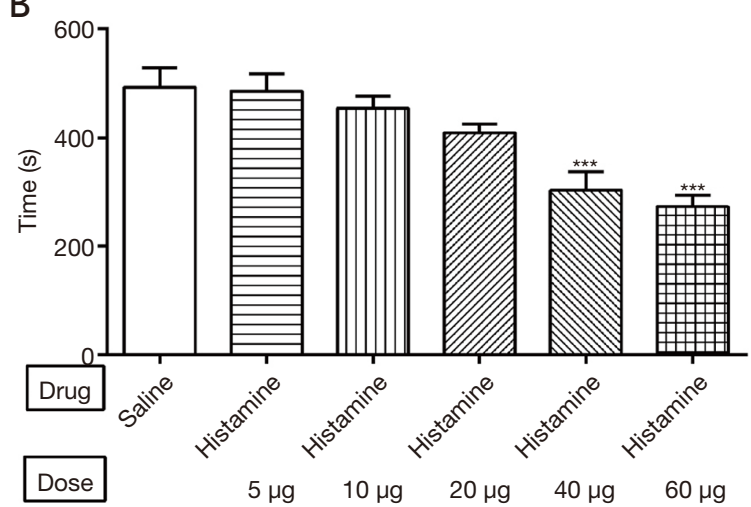

Figure 3 Injections of histamine (icv) decrease the emergence time. (A) Rats received propofol (10 mg/kg, iv) for induction of anesthesia, maintenance of anesthesia was achieved with continuous infusion of propofol at the rate of $40 \mathrm{mg} / \mathrm{kg} / \mathrm{h} \mathrm{for} 15 \mathrm{minutes}$. The rats received saline or histamine $(5 \mu \mathrm{L}$, icv) at 9 min after initiation of anesthesia. Emergence time was defined as the time from the termination of propofol infusion to regain of righting reflex; (B) column plot of emergence time for rats that received saline or histamine. ${ }^{* * *}, \mathrm{P}<0.001 v s$. saline (one-way ANOVA and Dunnett's test). 
A

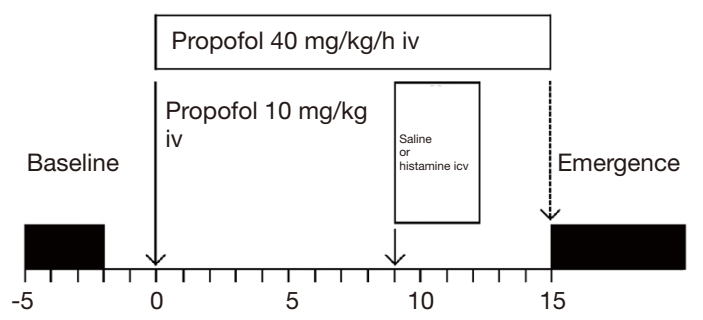

B

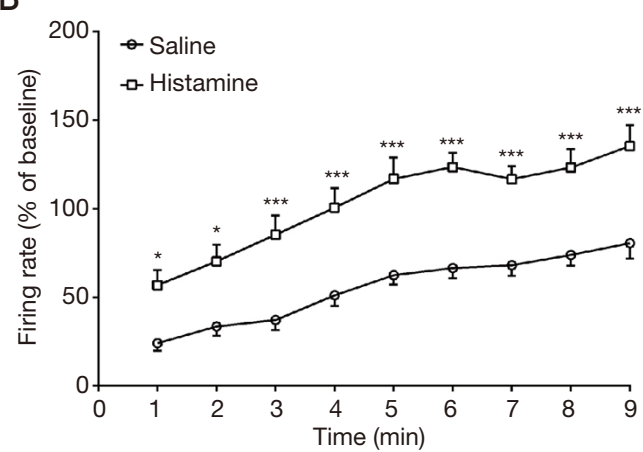

C

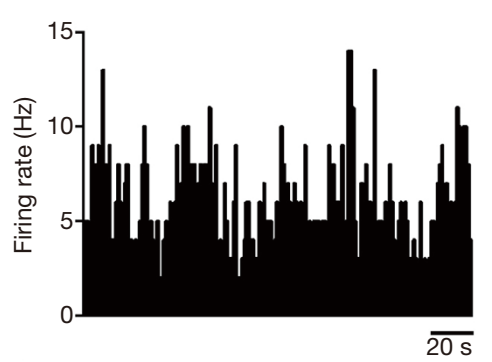

$\mathrm{D}$

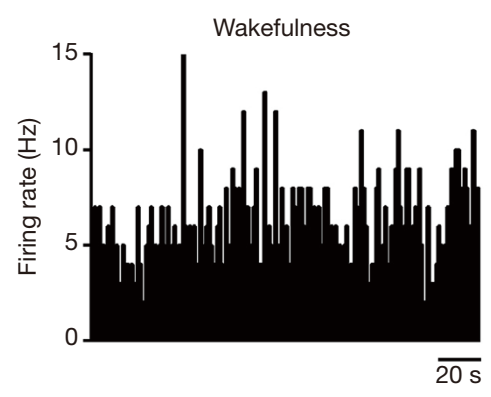

E

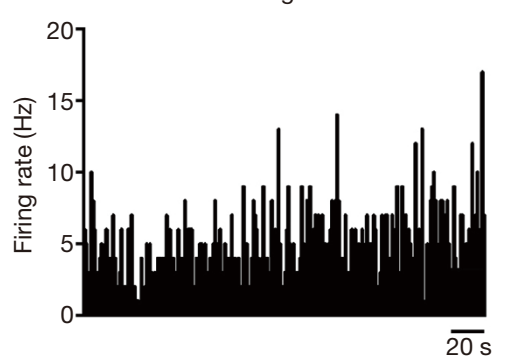

$\mathrm{F}$

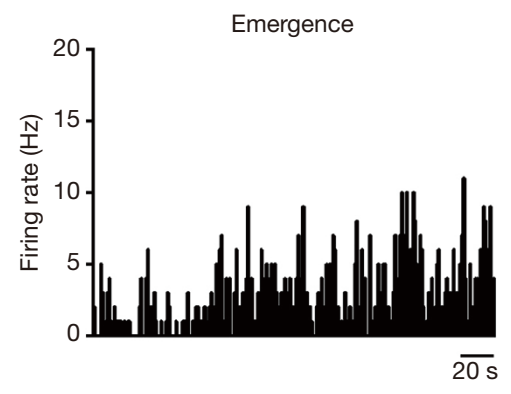

Figure 4 Injections of histamine (icv) increase the firing activity of mPFC neurons during emergence from propofol anesthesia. (A) The first 3-min window (black box) is used to compute the baseline firing rate before anesthesia, the second window is used to compute the firing activity during emergence; (B) time course of the changes in firing activities in $\mathrm{mPFC}$ neurons during emergence. The firing activities were converted to $\%$ of baseline (average firing rate with the bin width of $60 \mathrm{~s}$ during emergence/average firing rate during $180 \mathrm{~s}$ baseline) for each neuron. Repeated-measures two-way ANOVA was used to test the difference between the histamine group and the saline group. *, $\mathrm{P}<0.05 ;{ }^{* * *}, \mathrm{P}<0.001$ vs. saline. Example firing rate traces $(\mathrm{C}, \mathrm{D}, \mathrm{E}, \mathrm{F})$ recording from two neurons showing basal firing $(\mathrm{C}, \mathrm{D})$ and the response to histamine (E) and saline (F) during emergence. $\mathrm{mPFC}$, medial prefrontal cortex.

$(40 \mu \mathrm{g})$ on the firing activity of mPFC neurons during emergence. The protocol was displayed in Figure 4A, the firing activity was recorded during wakefulness and emergence, respectively. Histamine significantly increased the firing activity of $\mathrm{mPFC}$ neurons during emergence compared with the saline group [saline, $\mathrm{n}=9$; histamine, $\mathrm{n}=7$; repeated-measures two-way ANOVA: treatment, $\mathrm{F}_{(1,14)}=25.41, \mathrm{P}<0.001$; time, $\mathrm{F}_{(8,112)}=57.93$, $\mathrm{P}<0.001$; interaction, $\mathrm{F}_{(8,112)}=1.739, \mathrm{P}=0.0856$ ] (Figure $4 B$ ). Representative illustrations of the firing of two mPFC neurons during wakefulness were shown in Figure $4 C, D$ and the corresponding changes during emergence were demonstrated in Figure 4E, F.

\section{The $\mathrm{H}_{1}$ but not the $\mathrm{H}_{2}$ receptor antagonist reverses the decrease of the emergence time conferred by histamine}

To determine the specific receptor underlying the emergence-promoting effect, histamine or saline was injected into the LV following pretreatment with saline or $\mathrm{H}_{1}$ receptor antagonist triprolidine or $\mathrm{H}_{2}$ receptor antagonist cimetidine (Figure 5A). As shown in Figure 5B, the emergence time was significantly decreased in the saline + histamine group ( $\mathrm{n}=7,286.86 \pm 31.11 \mathrm{~s})$ compared with the saline group $[\mathrm{n}=8,506.63 \pm 26.17 \mathrm{~s}$; one-way ANOVA, $\mathrm{F}_{(5,38)}=17.079, \mathrm{P}<0.001$; Dunnett's test, $\left.\mathrm{P}<0.001\right]$. However, it was reversed by the pre-treatment with the $\mathrm{H}_{1}$ receptor antagonist triprolidine $(\mathrm{n}=7,497.71 \pm 23.49 \mathrm{~s}$; Dunnett's test, $\mathrm{P}<0.001$ compared with the saline + histamine group) but not $\mathrm{H}_{2}$ receptor antagonist cimetidine $\left(\mathrm{n}=8,329.38_{ \pm}\right.$ 20.67 s; Dunnett's test, $\mathrm{P}=0.649$ compared with the saline + histamine group). The triprolidine + saline group $(\mathrm{n}=7$, $540.29 \pm 27.62 \mathrm{~s})$ but not the cimetidine + saline group $(\mathrm{n}=7$, $480.57 \pm 22.42 \mathrm{~s}$ ) prolonged the emergence time compared with the saline group (Dunnett's test, $\mathrm{P}=0.815$; Dunnett's test, $\mathrm{P}=0.923$ ). 
A

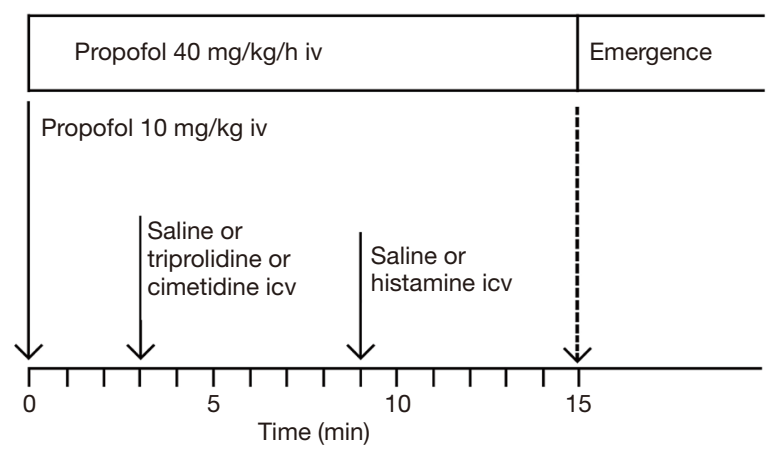

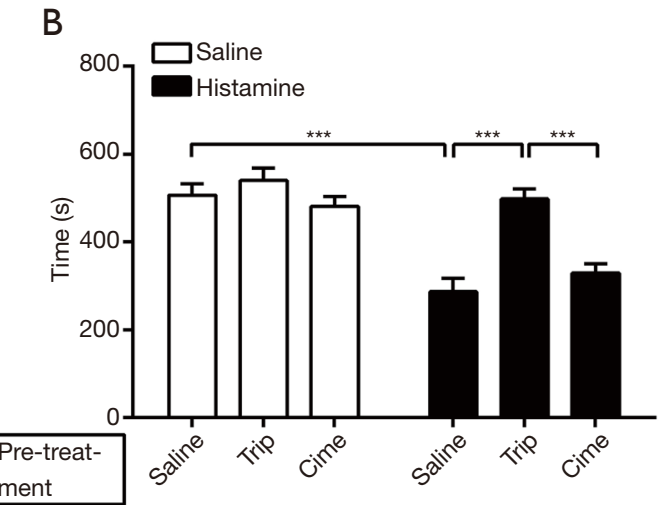

Figure 5 Triprolidine but not cimetidine reverses the decrease of the emergence time induced by histamine. (A) The rats received histamine or saline following pretreatment with saline or triprolidine or cimetidine; (B) the emergence time was markedly decreased in the saline + histamine group as compared to the saline group (Dunnett's test, ${ }^{* * *}, \mathrm{P}<0.001$ ), and this was reversed by pretreatment with triprolidine (Dunnett's test, ${ }^{* * *}, \mathrm{P}<0.001$ compared with the saline + histamine group) but not cimetidine (Dunnett's test, $\mathrm{P}=0.649$ compared with the saline + histamine group). Neither triprolidine + saline group nor cimetidine + saline group prolonged the emergence time as compared to saline + saline group. Trip, triprolidine; Cime, cimetidine.

\section{Dynamics of spontaneous firing activity of presumed histaminergic neurons}

Neurons were presumed to be histaminergic neurons based on the following criteria: the electrophysiological characteristics (action potentials of long duration and low firing rate) of the cells, the firing characteristics of neighboring neurons, and the microelectrode location. A total of 9 presumed histaminergic neurons were recorded, the waveforms were shown in Figure $6 A, B$, and the representative trace was illustrated in Figure $6 C, D, E$. The neurons displayed a tonic firing pattern, fired spontaneously at the average rate of $3.61 \pm 0.13 \mathrm{~Hz}$ during wakefulness (Figure $6 F$ ). By contrast, the average firing rate was $0.05 \pm 0.01 \mathrm{~Hz}$ during propofol anesthesia (Figure $6 F$ ). Two out of nine neurons were quiescent (Figure 6D). Then, we calculated the spontaneous activity during emergence, the time course of the changes was shown in Figure 6G. There was a dramatic increase in firing activity at about 4-6 min after stopping the infusion of propofol.

\section{Bidirectional manipulations of emergence through local injections into TMN}

Saline $(0.2 \mu \mathrm{L} / \mathrm{side})$ or ciproxifan $(1.0 \mu \mathrm{g} / \mathrm{side})$ or GABA $(10 \mu \mathrm{g} / \mathrm{side})$ was directly injected into TMN through the bilateral cannulae. The rats that received saline as the control group, had regained the righting reflex within an average time of $457.0 \pm 25.17 \mathrm{~s}(\mathrm{n}=8)$. Injection of GABA $(\mathrm{n}=8,665.40 \pm 44.87 \mathrm{~s})$ resulted in an obvious delay in emergence time [one-way ANOVA, $\mathrm{F}_{(2,21)}=39.93, \mathrm{P}<0.001$; Dunnett's test, $\mathrm{P}<0.001$ ] (Figure $7 A$ ). Conversely, the emergence time was significantly decreased to $266.4 \pm$ $13.99 \mathrm{~s}(\mathrm{n}=8)$ by injection of ciproxifan compared with the saline group (Dunnett's test, $\mathrm{P}<0.001$ ). A similar tendency was found in the firing activity of $\mathrm{mPFC}$ neurons, which was consistent with the behavior test. As shown in Figure 7B, GABA significantly suppressed the firing activity of $\mathrm{mPFC}$ neurons during emergence compared with saline [saline, $\mathrm{n}=8$; GABA, $\mathrm{n}=7$; ciproxifan, $\mathrm{n}=7$; repeated-measures twoway ANOVA: treatment, $\mathrm{F}_{(2,19)}=17.78, \mathrm{P}<0.001$; time, $\mathrm{F}_{(10,190)}=71.78, \mathrm{P}<0.001$; interaction, $\mathrm{F}_{(20,190)}=1.598$, $\mathrm{P}=0.0564]$. Though there was no significant difference until 6 min after stopping the infusion of propofol, the firing activity was still lower than saline even at $11 \mathrm{~min}$, when most rats regained the righting reflex. Conversely, ciproxifan significantly increased the firing activity across the period of emergence $(\mathrm{P}<0.05)$.

\section{Discussion}

This study reveals a critical role of the histaminergic system in the emergence of propofol anesthesia. Injections of histamine into the LV decreased the emergence time and exert an excitatory effect on the firing activity of $\mathrm{mPFC}$ neurons, which demonstrated that histamine accelerates emergence from propofol anesthesia. Though neither $\mathrm{H}_{1}$ 
A

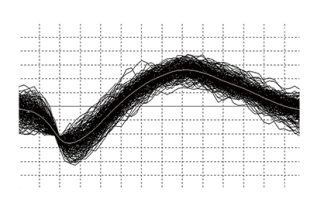

B

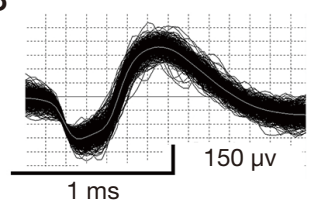

D

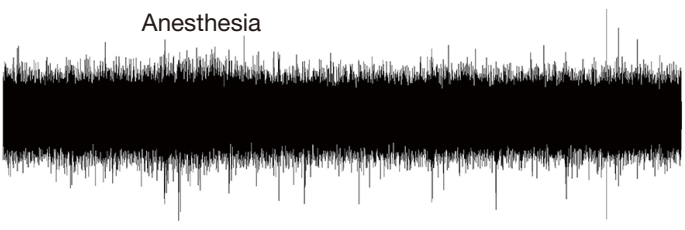

$5 \mathrm{~s}$

$E$

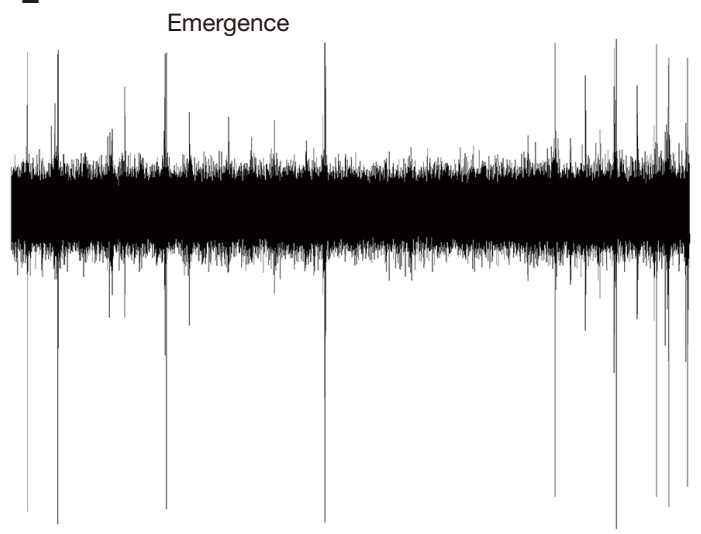

G

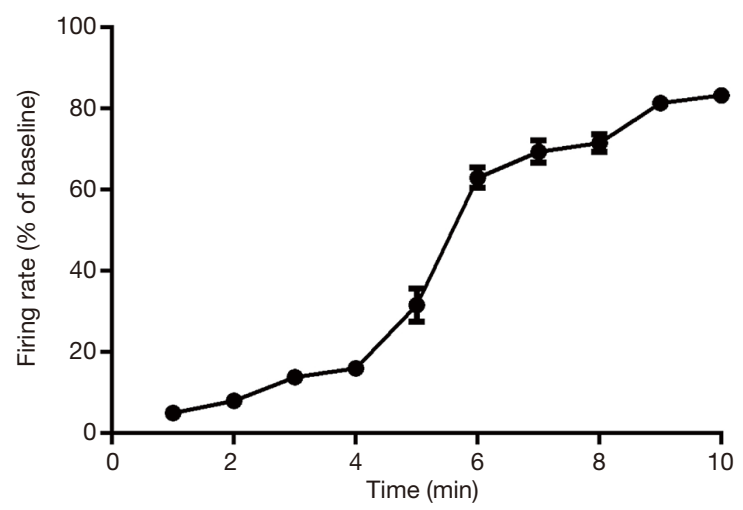

Figure 6 Dynamics of spontaneous firing activities of the presumed histaminergic neuron. (A) Examples of action potentials with longduration recorded from a presumed histaminergic neuron; (B) examples of action potentials recorded from a neighboring neuron; (C,D,E) action potential tracings of a presumed histaminergic neuron during wakefulness (C), propofol anesthesia (D), and emergence (E); (F) the neurons fire at a low rate during wakefulness, while almost keep silent during propofol anesthesia. Data lines are the spontaneous firing activity of individual neurons, horizontal bars mark the average firing rate; (G) time course of the changes of spontaneous firing activities during emergence from propofol anesthesia.

receptor antagonist triprolidine nor $\mathrm{H}_{2}$ receptor antagonist cimetidine prolonged the emergence time, emergencepromoting induced by histamine could be reversed by triprolidine but not cimetidine. Furthermore, local injections into the TMN of a potent $\mathrm{H}_{3}$ receptor inverse agonist ciproxifan also accelerated emergence. By contrast, a major inhibitory neurotransmitter, GABA, delayed emergence from propofol anesthesia.

Extensive networks of histaminergic fibers were detected in many areas of the rat brain $(12,27)$, suggesting that histamine is a neurotransmitter in the central nervous system (28). Accumulative evidence shows that histaminergic neurons play a critical role in the regulation of many physiological functions (29), including the sleep- 
A

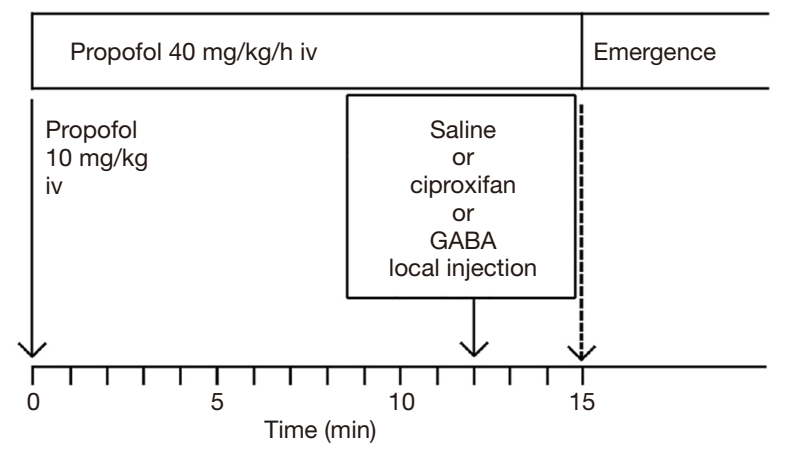

B

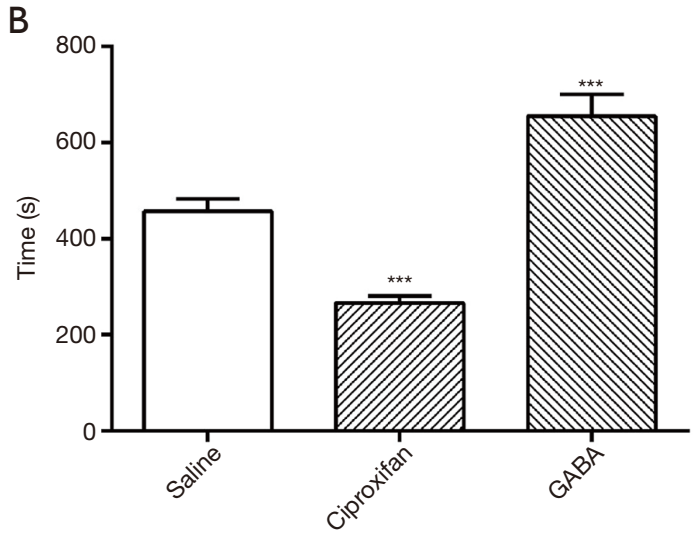

C

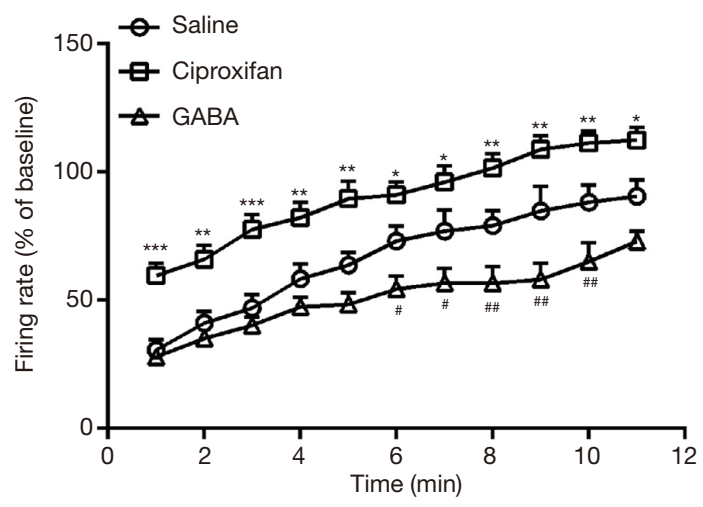

Figure 7 Bidirectional manipulations of emergence through local injections into TMN. (A) Rats received saline or ciproxifan or GABA at 12 min after initiation of anesthesia; (B) column plot of emergence time for rats that received saline or GABA or ciproxifan. ***, $\mathrm{P}<0.001$ vs. saline (one-way ANOVA and Dunnett's test); (C) GABA suppressed the firing activity of mPFC neurons during emergence, while ciproxifan significantly increased the firing activity across the period of emergence. ${ }^{*}, \mathrm{P}<0.05 ;{ }^{* *}, \mathrm{P}<0.01 ;{ }^{* * *}, \mathrm{P}<0.001$ vs. saline. ${ }^{*}, \mathrm{P}<0.05$; ${ }^{\#}, \mathrm{P}<0.01$ (repeated-measures two-way ANOVA). GABA, gamma-aminobutyric acid.

wake cycle (30). A circadian rhythm in the release of histamine in the posterior hypothalamus has been observed at the moment of awakening and a high release rate is maintained during wakefulness (31). While histidine decarboxylase (HDC) knockout mice which lack the key enzyme responsible for histamine synthesis, have increased sleep and displayed a deficit in wakefulness (32). Similarly, it is well known that the first-generation $\mathrm{H}_{1}$ receptor antagonists could produce considerable sedation due to easy permeability through the blood-brain barrier (33). These results imply that histamine play a key role in maintaining wakefulness, even more, is termed as a "waking substance". However, despite the numerous findings in the sleepwake cycle in animal models, not until recently does the effect of the histaminergic system on general anesthesia have been determined. Rats with bilateral TMN lesions showed a prolonged emergence time when undergoing isoflurane anesthesia (17). In the present study, we found intracerebroventricular injections of exogenous histamine decreased the emergence time in a dose-dependent manner, moreover, local injection of ciproxifan also decreased the emergence time. Additionally, our preliminary study suggested that peripheral injection of histamine through the tail vein exhibits no effect on emergence time. It implied that increasing histamine content in the central nervous system rather than peripheral blood promotes emergence.

The cognitive functions are mainly provided by the mPFC $(21,22)$, which is particularly sensitive to general anesthesia. Neurons in PFC integrates sensory or information to perform cognitive progression, and the $\mathrm{mPFC}$ progressively recovers its crucial functional competence for use during emergence. We found that firing activities of mPFC neurons both in the saline group and histamine group were increased over time during emergence from propofol anesthesia, and histamine had an excitatory effect on the firing activity. It suggests that histamine may 
promote the recovery of cognition after emergence. Indeed, an increasing number of studies confirm the possible relevance of histamine in cognition (34-36).

Histaminergic actions in the central nervous system are the result of histamine released by histaminergic neurons, whereas the histamine contribution from the mast cells is quite limited (29). Histaminergic neurons are exclusively located in TMN, a region of the posterior hypothalamus. We found the presumed histaminergic neurons fired at an average rate of $3.61 \pm 0.13 \mathrm{~Hz}$ during wakefulness, which was consistent with previous in vivo studies $(37,38)$. Two out of nine neurons are silent during anesthesia, while the other neurons displayed a dramatic decrease in the firing rate. Other studies have shown that histaminergic neurons ceased firing during sleep (38). Electrophysiology has shown that the activity of histaminergic neurons is high during wakefulness and low or even silent during sleep in freely moving cats (26). Collectively, our findings are consistent with previous studies that histaminergic neurons fired in a state-dependent manner. Systemic administration of anesthetic agent pentobarbital and propofol produces a significant reduction in c-Fos protein, a marker of neuronal activation in TMN (13). Similar change pattern is observed during nature sleep (14). It seemed to support the view that general anesthesia and sleep might share some common neural substrates. Moreover, we found that the changes in firing activity of presumed histaminergic neurons were earlier than the transitions from anesthesia to wakefulness, with dramatic changes during 4-6 min after stopping the infusion of propofol.

The $\mathrm{H}_{3}$ receptor functions as an auto-receptor on somata, dendrites, and axons of TMN neurons, regulates the synthesis and release of histamine (29). Blockade of $\mathrm{H}_{3}$ receptor could promote cell firing, as well as histamine synthesis and release (39). The TMN receives major inhibitory GABAergic inputs that originated from the ventrolateral preoptic nucleus (40) and the GABAergic innervation plays a key role in silencing the histaminergic system during sleep (41). Thus, we bidirectionally modulate the activity of TMN neurons through local injection of ciproxifan and GABA. Similar to the administration of histamine, local injections of ciproxifan decrease the emergence time as well as increase the firing activity of mPFC neurons. As a heteroreceptor, $\mathrm{H}_{3}$ receptors also locate on other cell dendrites and axons, and blockade of $\mathrm{H}_{3}$ receptors also modulate other neurotransmitters in the brain, such as 5-HT and norepinephrine. We avoid this effect by local injection. we confirm the fact that ciproxifan exerts wake-promoting effects, which also exist in emergence from propofol anesthesia. We used GABA but not an $\mathrm{H}_{3}$ receptor agonist to deactivate the TMN neurons to mimic the physical inhibition, which was due to that the GABA released from GABAergic projections. Our study showed that GABA could prolong the emergence time as well as inhibit the firing activity of mPFC neurons, which was consistent with other studies showing that bilateral injection of GABA receptor agonist muscimol into the TMN increased the duration of loss of righting (17).

In conclusion, our findings suggest an important role of the central histaminergic system for the neural pathways that responsible for the sleep-wake cycle in wider fields of state transitions, such as emergence from propofol anesthesia. This study also has implications for clinical practice, indicating that any drugs that exert their effects through the central histaminergic system may also have effects on emergence from propofol anesthesia.

\section{Acknowledgments}

The authors thank Chao-Nan Yu (Qiushi Academy for Advanced Studies, Zhejiang University, Hangzhou, China) for technical support. And the authors thank Dr. Xiatian $\mathrm{Wu}$ for language editing.

Funding: This work was partly supported by the Natural Science Foundation of Zhejiang province (Grant No. Y18H090006).

\section{Footnote}

Reporting Checklist: The authors have completed the ARRIVE reporting checklist. Available at http://dx.doi. org/10.21037/apm-20-2594

Data Sharing Statement: Available at http://dx.doi. org/10.21037/apm-20-2594

Conflicts of Interest: All authors have completed the ICMJE uniform disclosure form (available at http://dx.doi. org/10.21037/apm-20-2594). The authors have no conflicts of interest to declare.

Ethical Statement: The authors are accountable for all aspects of the work in ensuring that questions related to the accuracy or integrity of any part of the work are appropriately investigated and resolved. Experiments were performed under a project license (No.: 2019-676) granted 
by the Animal Care Committee of Zhejiang University, in compliance with institutional guidelines for the care and use of animals.

Open Access Statement: This is an Open Access article distributed in accordance with the Creative Commons Attribution-NonCommercial-NoDerivs 4.0 International License (CC BY-NC-ND 4.0), which permits the noncommercial replication and distribution of the article with the strict proviso that no changes or edits are made and the original work is properly cited (including links to both the formal publication through the relevant DOI and the license). See: https://creativecommons.org/licenses/by-nc-nd/4.0/.

\section{References}

1. Brown EN, Lydic R, Schiff ND. General anesthesia, sleep, and coma. N Engl J Med 2010;363:2638-50.

2. Magni G, Rosa IL, Melillo G, et al. A comparison between sevoflurane and desflurane anesthesia in patients undergoing craniotomy for supratentorial intracranial surgery. Anesth Analg 2009;109:567-71.

3. Gupta A, Stierer T, Zuckerman R, et al. Comparison of recovery profile after ambulatory anesthesia with propofol, isoflurane, sevoflurane, and desflurane: a systematic review. Anesth Analg 2004;98:632-41, table of contents.

4. Lydic R. Fact and fantasy about sleep and anesthesiology. Anesthesiology 2002;97:1050-1.

5. Kelz MB, Sun Y, Chen J, et al. An essential role for orexins in emergence from general anesthesia. Proc Natl Acad Sci U S A 2008;105:1309-14.

6. Allada R. An emerging link between general anesthesia and sleep. Proc Natl Acad Sci U S A 2008;105:2257-8.

7. Franks NP, Zecharia AY. Sleep and general anesthesia. Can J Anaesth 2011;58:139-48.

8. Saper CB, Scammell TE, Lu J. Hypothalamic regulation of sleep and circadian rhythms. Nature 2005;437:1257-63.

9. Saper CB, Fuller PM, Pedersen NP, et al. Sleep state switching. Neuron 2010;68:1023-42.

10. Saper CB, Chou TC, Scammell TE. The sleep switch: hypothalamic control of sleep and wakefulness. Trends Neurosci 2001;24:726-31.

11. Franks NP. General anaesthesia: from molecular targets to neuronal pathways of sleep and arousal. Nat Rev Neurosci 2008;9:370-86.

12. Panula P, Yang HY, Costa E. Histamine-containing neurons in the rat hypothalamus. Proc Natl Acad Sci U S A $1984 ; 81: 2572-6$.
13. Nelson LE, Guo TZ, Lu J, et al. The sedative component of anesthesia is mediated by GABA(A) receptors in an endogenous sleep pathway. Nat Neurosci 2002;5:979-84.

14. Novak CM, Smale L, Nunez AA. Rhythms in Fos expression in brain areas related to the sleep-wake cycle in the diurnal Arvicanthis niloticus. Am J Physiol Regul Integr Comp Physiol 2000;278:R1267-74.

15. Zecharia AY, Nelson LE, Gent TC, et al. The involvement of hypothalamic sleep pathways in general anesthesia: testing the hypothesis using the GABAA receptor beta3N265M knock-in mouse. J Neurosci 2009;29:2177-87.

16. Luo T, Leung LS. Basal forebrain histaminergic transmission modulates electroencephalographic activity and emergence from isoflurane anesthesia. Anesthesiology 2009;111:725-33.

17. Luo T, Leung LS. Involvement of tuberomamillary histaminergic neurons in isoflurane anesthesia. Anesthesiology 2011;115:36-43.

18. Solt K, Van Dort CJ, Chemali JJ, et al. Electrical stimulation of the ventral tegmental area induces reanimation from general anesthesia. Anesthesiology 2014;121:311-9.

19. Vazey EM, Aston-Jones G. Designer receptor manipulations reveal a role of the locus coeruleus noradrenergic system in isoflurane general anesthesia. Proc Natl Acad Sci U S A 2014;111:3859-64.

20. Trantham-Davidson H, Burnett EJ, Gass JT, et al. Chronic alcohol disrupts dopamine receptor activity and the cognitive function of the medial prefrontal cortex. J Neurosci 2014;34:3706-18.

21. Robbins TW. From arousal to cognition: the integrative position of the prefrontal cortex. Prog Brain Res 2000;126:469-83.

22. Dalley JW, Cardinal RN, Robbins TW. Prefrontal executive and cognitive functions in rodents: neural and neurochemical substrates. Neurosci Biobehav Rev 2004;28:771-84.

23. Haas HL, Sergeeva OA, Selbach O. Histamine in the nervous system. Physiol Rev 2008;88:1183-241.

24. Paxinos G, Watson C. The rat brain in stereotaxic coordinates: hard cover edition. Academic Press, 2006.

25. Humbert-Claude M, Morisset S, Gbahou F, et al. Histamine $\mathrm{H} 3$ and dopamine D2 receptor-mediated [35S]GTPgamma[S] binding in rat striatum: evidence for additive effects but lack of interactions. Biochem Pharmacol 2007;73:1172-81.

26. Vanni-Mercier G, Gigout S, Debilly G, et al. Waking 
selective neurons in the posterior hypothalamus and their response to histamine $\mathrm{H} 3$-receptor ligands: an electrophysiological study in freely moving cats. Behav Brain Res 2003;144:227-41.

27. Inagaki N, Yamatodani A, Ando-Yamamoto M, et al. Organization of histaminergic fibers in the rat brain. J Comp Neurol 1988;273:283-300.

28. Nowak JZ. Histamine in the central nervous system: its role in circadian rhythmicity. Acta Neurobiol Exp (Wars) 1994;54 Suppl:65-82.

29. Haas H, Panula P. The role of histamine and the tuberomamillary nucleus in the nervous system. Nat Rev Neurosci 2003;4:121-30.

30. Thakkar MM. Histamine in the regulation of wakefulness. Sleep Med Rev 2011;15:65-74.

31. Mochizuki T, Yamatodani A, Okakura K, et al. Circadian rhythm of histamine release from the hypothalamus of freely moving rats. Physiol Behav 1992;51:391-4.

32. Parmentier R, Ohtsu H, Djebbara-Hannas Z, et al. Anatomical, physiological, and pharmacological characteristics of histidine decarboxylase knock-out mice: evidence for the role of brain histamine in behavioral and sleep-wake control. J Neurosci 2002;22:7695-711.

33. Hindmarch I, Shamsi Z. Antihistamines: models to assess sedative properties, assessment of sedation, safety and other side-effects. Clin Exp Allergy 1999;29 Suppl $3: 133-42$.

Cite this article as: Xia C, Zhao Z, Yu L, Yan M. The role of the central histaminergic system in emergence from propofol anesthesia in rats model. Ann Palliat Med 2021;10(6):60676078. doi: 10.21037/apm-20-2594
34. van Ruitenbeek P, Vermeeren A, Riedel WJ. Histamine H1 receptor antagonist cetirizine impairs working memory processing speed, but not episodic memory. Br J Pharmacol 2010;161:456-66.

35. Dai H, Kaneko K, Kato H, et al. Selective cognitive dysfunction in mice lacking histamine $\mathrm{H} 1$ and $\mathrm{H} 2$ receptors. Neurosci Res 2007;57:306-13.

36. Passani MB, Bacciottini L, Mannaioni PF, et al. Neurosci Biobehav Rev 2000;24:107-13.

37. Takahashi K, Lin JS, Sakai K. Neuronal activity of histaminergic tuberomammillary neurons during wakesleep states in the mouse. J Neurosci 2006;26:10292-8.

38. Sakai K, Takahashi K, Anaclet C, et al. Sleep-waking discharge of ventral tuberomammillary neurons in wildtype and histidine decarboxylase knock-out mice. Front Behav Neurosci 2010;4:53.

39. Schwartz JC. The histamine H3 receptor: from discovery to clinical trials with pitolisant. Br J Pharmacol 2011;163:713-21.

40. Sherin JE, Elmquist JK, Torrealba F, et al. Innervation of histaminergic tuberomammillary neurons by GABAergic and galaninergic neurons in the ventrolateral preoptic nucleus of the rat. J Neurosci 1998;18:4705-21.

41. Griebel G, Decobert M, Jacquet A, et al. Awakening properties of newly discovered highly selective $\mathrm{H}(3)$ receptor antagonists in rats. Behav Brain Res 2012;232:416-20. 